\title{
Listening to the experts: is there a place for food taxation in the fight against obesity in early childhood?
}

\author{
Erin Pitt ${ }^{1 *}$, Elizabeth Kendall ${ }^{2}$, Andrew P Hills ${ }^{3}$ and Tracy Comans ${ }^{1}$
}

\begin{abstract}
Background: Childhood obesity is a global public health problem as a result of poor eating and activity behaviours. Periodically, taxation has been proposed as a strategy to modify food purchasing behaviour, and once again, there is growing interest in the feasibility of this approach towards obesity prevention. This article examines the outcomes of an expert panel that was convened to obtain consensus on 1) which foods are most problematic in terms of obesity if consumed during early childhood and 2) which foods would be amenable to taxation as a strategy to reduce consumption. A nominal group technique was facilitated with a panel of 12 Australian experts including nutrition professionals, academics and clinicians with an interest in childhood obesity. In addition to routine ranking analysis, transcripts were explored using thematic analysis to reveal the collective beliefs of the experts.
\end{abstract}

Results: The panel reached consensus about the types of foods that were problematic in terms of their consumption and contribution to early childhood obesity which included prepared foods consumed outside the home, high protein infant formula products and sugar-sweetened beverages. However of these food and beverage items, the panel only deemed sugar-sweetened beverages and infant formula to be potentially amenable to taxation. They also highlighted the importance of subsidizing fresh fruit and vegetables, whole and unprocessed foods and hence topic complexities resulted in panel discussion being extended beyond the central notion of taxation.

Conclusions: The panel identified several food groups that contributed to early childhood obesity but noted that these foods were not equally amenable to taxation. Results of this research should be considered during decision making and planning regarding population policy and regulation to reduce childhood obesity in the very early years.

Keywords: Food, Taxation, Childhood obesity, Nominal group technique, Exert panel

\section{Background}

The incidence and prevalence of overweight and obesity has been escalating around the world over the past few decades, including in the early childhood years [1-3]. The most recent data from the 2011-2012 Australian Health Survey indicates that $25.1 \%$ of children aged 2 to 17 years were overweight or obese, including $18.2 \%$ overweight and $6.9 \%$ obese based on Body Mass Index (BMI) [4]. Although some recent literature suggests childhood obesity may be starting to plateau in parts of

\footnotetext{
* Correspondence: e.pitt@griffith.edu.au

'Population and Social Health Research Program, Griffith Health Institute, Griffith University, Logan Campus, University Drive, Meadowbrook, QLD 4131, Australia

Full list of author information is available at the end of the article
}

Australia [5,6], the condition continues to be a global public health priority [7] and there is consensus regarding an urgent need for government to take rapid action [8].

Eating habits are established early in life and many dietary behaviours are maintained during the growing years and throughout adulthood [9-11]. Hence obesity and poor eating behaviours in childhood are potential risk factors for adult overweight and obesity [12]. It is therefore of utmost importance to direct obesity interventions towards the very early years of life $[1,13]$.

Many researchers in public health have attributed the increase in obesity rates to an increasingly obesogenic environment $[14,15]$. If we agree that the environment, including the food environment, has a major impact on childhood obesity, there are several potential policy 
levers available to influence food choices; some of which include price, availability and marketing. Taxation has been suggested and investigated as a strategy to influence price and therefore modify food purchasing behaviour [16] and subsequent consumption, and is a growing area of interest in the prevention of obesity $[17,18]$. The interest in taxation to combat obesity is warranted given other public health successes such as the reduction of tobacco and alcohol consumption $[19,20]$.

Various countries have implemented food taxation on certain groups of foods including soft drinks, snack foods and fat [21]. While it has been demonstrated that price increases on food negatively affect consumption [22], evidence on the real world effectiveness of taxation to reduce obesity rates is limited and the feasibility of taxing some food groups is unclear, particularly in the light of strong industry opposition and repeals of taxes that have occurred in the United States and Denmark [20,23].

In the presence of insufficient, inadequate or conflicting evidence, it is useful to turn to expert opinion for clarity. Obtaining expert opinion through methods of consensus also derives first-hand accounts from researchers and clinicians, enabling decisions that capitalise on their experience and expertise [24,25]. Consensus methods are useful in determining research priorities through the generation of priority qualitative information that is both relevant and reliable [26]. Consensus building methods can address individual discrepancies and reach shared or collective agreement about a way forward but still retain the diversity of different perspectives [27].

This paper describes a consensus-based investigation of Australian experts aimed at identifying foods that are most problematic in terms of consumption during early childhood and those that might also be amenable to taxation as a strategy to reduce consumption. Our research addresses a gap in the literature around the understanding of the relative importance of particular food groups to obesity development in early childhood and the responsiveness of these foods to taxation from the unique perspective of academics, researchers, clinicians and policy makers. This paper also reports on the use of a systematic consensus-building method - the nominal group technique, as a tool for identifying priority foods with the potential to respond to taxation.

\section{Methods}

We applied the nominal group technique [28] which enables a selected group of participants to generate and share ideas, undertake discussion to clarify those ideas and then rank ideas to identify the top priorities for all group members [29]. This process permits effective group decision-making and builds consensus by allowing contentious issues to be addressed collectively. It enables the simplification of complex areas and establishment of priorities at the same time as fostering in-depth discussion of issues surrounding the topic $[28,30]$.

\section{Participants}

A list of potential expert panel members was constructed by Chief Investigators and team members and was achieved using a combination of methods. Prominent publications and literature were reviewed as identified through literature searches relating to childhood obesity, nutrition, taxation and public policy in the Australian context. Snowballing and purposive sampling was also used to ensure inclusion of key organizations (e.g. Food Standards Australian and New Zealand (FSANZ)) as well as government public health departments and universities. Criteria for inclusion as a member of the panel included holding a position in Australia as a researcher, teaching academic or clinician with significant experience, contribution and public presence in a combination of areas of areas including nutrition, public policy and childhood obesity. Experience and contribution was deemed significant based on a track record of international journal publications, speaker invitations or involvement in relevant professional organisations.

Participants were purposively sampled to ensure that the final mix of invited experts represented both clinical and research fields. Fifteen experts were invited to attend, with three people unable to participate. The final panel was comprised of twelve Australian experts, including five clinicians, two researchers and five people with dual roles in both research and academia. Ethics approval for this research was obtained through the Griffith University Human Research Ethics Committee (HREC - MED/32/ 12/HREC). Written informed consent to participate was obtained from all members of the panel.

\section{Procedure}

Experts were provided with pre-reading material during the week prior to the panel discussion. The material summarised the epidemiology of childhood obesity, trends in expenditure, consumption and commercial sales of key categories of foods; particularly beverages (e. g. sugar-sweetened and artificially sweetened) and unhealthy foods (e.g. take-away foods, snacks and confectionary). No interpretation or discussion of the facts was provided.

The expert panel was a closed event held at a hotel near to Brisbane airport to accommodate travel arrangements of inter-state panel members. The panel convened for 3.5 hours which commenced with a welcome and introduction session followed by a presentation of background information, a summary of the evidence and an outline of the purpose of the meeting. Four members of the research team were present to record and manage the process. The panel discussion was facilitated and all 
sessions were audio recorded with written consent of participants.

The first stage of the nominal group technique required panel members to individually identify key foods that they considered to be the strongest contributors to obesity in early childhood. Panel members then individually presented their top idea to the larger group. Members each presented a single idea without significant discussion. The technique requires participants to present only one idea and not to engage in discussion about each idea until later. However in reality it is necessary to accommodate the flow of the discussion, subsequently minor discussion was allowed and other relevant ideas of importance that were nominated out of sequence were recorded. Each idea was written on large format paper and placed around the room for later clarification. The clarification process involved group discussion about the nature of the idea, the overlap amongst ideas and any definitions that needed to be refined.

Once all the ideas were exhausted and clarified they remained on display around the room for panel members to view. Panel members were then asked to vote for their top priorities. Members were each given five stickers numbered one to five which they were asked to place alongside their top priorities (i.e. the foods that they believed would most impact on obesity if consumption was reduced), with five representing the most important idea (i.e. the most points). Multiple points could be allocated to a single idea if desired.

Votes given to each idea were totalled to identify the ideas that were considered most important to the entire group. The top priorities were then described in more detail and subjected to a group discussion about how influential and feasible implementation of taxation would be in relation to the identified food items. The discussion focused on price elasticity for each of the top priorities (i.e. how much would consumption of this food item change if price increased), substitution (i.e. is there a close substitute that may be more or less healthy) and practicality (i.e. what would be the barriers to, or facilitators of, taxation).

\section{Data analysis}

The panel discussion was transcribed verbatim and stored in NVivo 10.0. Identification of key themes from transcripts was undertaken with qualitative analysis software by one author (E.P.). Coding of themes was validated through cross checking by a second author (T.C.) with additional discussion to resolve discrepancies.

\section{Results}

\section{Identifying and prioritising key foods}

"What is it that causes obesity? Well, any drink, which contains calories, any food, which contains calories."
Through the Nominal Group Technique, a number of problem foods and other important factors associated with childhood obesity were identified. The outcome of voting can be seen in Table 1 . The first column contains the number of votes allocated to each category of food, with larger votes indicating higher priority based on the perceived importance to childhood obesity.

Table 1 Key foods and other relevant issues/factors contributing to obesity in $\mathbf{0}$ to $\mathbf{5}$ year old children

\begin{tabular}{|c|c|}
\hline Number of votes ${ }^{a}$ & Identified key foods, issues and factors \\
\hline Total: 66 votes & Sweetened drinks \\
\hline Soft drinks: 25 votes & - Soft drinks (carbonated beverages) \\
\hline \multirow[t]{4}{*}{ Sweet drinks: 41 votes } & - Cordials \\
\hline & - Other sugar-sweetened beverages \\
\hline & - High fat and sweetened flavoured milks \\
\hline & - Fruit juice, fruit drinks and vitamin waters \\
\hline Total: 32 votes & Portion-packed snacks and portion sizes \\
\hline $\begin{array}{l}\text { Portion-packed snacks: } \\
16\end{array}$ & - Tiny Teddies \\
\hline votes & - Individually wrapped packs \\
\hline Portion sizes: 9 & $\begin{array}{l}\text { - Sweet and savoury snacks such as cake bars, } \\
\text { chocolates and muffins }\end{array}$ \\
\hline Chips: 7 votes & - Packets of chips \\
\hline \multirow[t]{4}{*}{26 Votes } & $\begin{array}{l}\text { Increase consumption of fruit, vegetables, } \\
\text { legumes, whole grain cereals and milk, } \\
\text { yoghurt and cheese }\end{array}$ \\
\hline & $\begin{array}{l}\text { - Remove tax deduction on advertising and } \\
\text { subsidizing freight or removing tax on } \\
\text { freight of healthy foods }\end{array}$ \\
\hline & $\begin{array}{l}\text { - Tax particular foods in order to subsidize } \\
\text { fruit and vegetables }\end{array}$ \\
\hline & $\begin{array}{l}\text { - Position fruit and vegetables as healthy } \\
\text { alternatives through use of subsidies to } \\
\text { increase equity of access }\end{array}$ \\
\hline Total: 20 votes & Fast foods \\
\hline Fast food: 13 votes & $\begin{array}{l}\text { - Well known icons such as McDonald's } \\
\text { Hungry Jack's, Red Rooster and Subway etc. }\end{array}$ \\
\hline \multirow[t]{5}{*}{ 'Red foods': 7 votes } & $\begin{array}{l}\text { - Drive through, up-sizing and } 24 \text { hour } \\
\text { operation }\end{array}$ \\
\hline & - Serving size \\
\hline & - Advertising \\
\hline & - Energy fat, sugar and sodium content \\
\hline & - Provision of 'meals' \\
\hline \multirow[t]{3}{*}{15 votes } & Infant formula \\
\hline & - High protein infant formula products \\
\hline & - Follow on formula for toddlers \\
\hline \multirow[t]{3}{*}{13 votes } & Processed meats and meat alternatives \\
\hline & - Chicken nuggets and sausages \\
\hline & - High fat and sodium content \\
\hline
\end{tabular}

${ }^{\mathrm{a}} 12$ experts had a total of 15 votes each to allocate. The total votes should add to 180 , thus there are 8 votes that cannot be accounted for. 
The voting process revealed a clear consensus among the experts that the most problematic food group was sweetened beverages. The experts agreed that reducing consumption of sugar-sweetened drinks would impact most significantly on childhood obesity. Although achieving less than half the votes allocated to sugar-sweetened drinks, portion-packed snacks and take-away foods were also considered problematic for childhood obesity. Of slightly lower importance were high protein infant formula products and processed meats. Experts believed that an important strategy was to increase consumption of fresh foods with high nutrient content.

\section{Determining the ability to influence consumption}

Following the initial voting, panel members discussed the amenability of each food group to influences on consumption such as taxation. In discussing the potential influence of taxation, panel members considered the extent to which price influenced consumption. Additionally, the panel unanimously agreed that food taxation efforts should also consider means to increase the consumption of healthy foods consistent with the Australian Dietary Guidelines and The Australian Guide to Healthy Eating. Particularly through means such as subsidies, increasing consumption of healthy foods was viewed by the panel as a potentially acceptable strategy to society that would enable equity regardless of financial means and might facilitate a greater level of impact in reducing consumption of problem foods in early childhood.

The notion of product substitution was also raised by the panel when contemplating how food consumption is influenced by price (i.e. the extent to which a particular product would be replaced by another product of either greater or lower health value). The panel noted that increasing the price of some food and beverage items through taxation could successfully reduce consumption, but in many cases they identified alternative products that could potentially be less healthy.

The panel agreed that sugar-sweetened drinks could be amenable to taxation as most drinks represented relatively distinct products that could be easily defined; however, they noted some complexity in relation to the impact of taxation. They provided examples of the way in which the beverage industry actively promoted product substitution in response to price fluctuations. For example, as $100 \%$ fruit juice increased in price, beverage companies began marketing substantially cheaper sweetened fruit drinks with lower percentages of juice content.

"...substitution has been shown in juices and juice drinks so that juice drinks have had increases in sales... and some of the juice drinks that have 25-50\% juice have gone up [in price] and the pure fruit juices haven't so the people have been substituting those because they are a lot cheaper..."

They also noted that taxation on sugar-sweetened drinks may have no effect on product substitution depending on the nature of the product or brand. Some expensive brands of soft drink, for instance, are so popular that preferences may not be substantially altered by price increases. Aside from product substitution, another perspective provided by a panel member raised the notion that consumers should either be having less of unhealthy foods or having nothing, instead of substituting:

“...we talk about...substituting food, when ultimately, from my perspective, another message is actually having less. It seems to be lost in this whole thing about what should we be having instead of something, well, the answer is nothing."

The panel discussed the role of high protein infant formula in contributing to obesity. They mentioned this particular group of products is usually of lower quality and is an unnecessary product for young children in the general population above the age of 12 months, who can gain all nutritional requirements from a regular adult diet. Thus the panel felt this distinct group of products would be amenable to taxation to reduce consumption. Panel members mentioned the potentially regressive nature of tax on this particular product however this was not discussed in detail, nor were comment made on the influence of taxation for lower income groups.

\section{Consensus outcomes}

Final voting resulted in consensus on four dominant foods and concepts. Consensus outcomes can be seen in Table 2. Sugar-sweetened drinks and low quality infant and toddler formula products were identified as reasonable and practical to apply taxation. In addition to this, the panel unanimously felt subsidizing healthy foods was of utmost importance. In terms of prepared foods consumed outside the home and other food groups discussed, panel members agreed that they would not be amenable to taxation; not because they were insensitive

\section{Table 2 Final consensus}

\begin{tabular}{|c|c|}
\hline 1. & Prepared foods consumed outside the home ${ }^{a} \mathrm{c}$ \\
\hline 2. & High protein infant formula products ${ }^{a} b$ \\
\hline 3. & Sugar-sweetened drinks ${ }^{a} b$ \\
\hline 4. & Subsidizing fresh fruit and vegetables; whole and unprocessed foods \\
\hline
\end{tabular}


to price fluctuations, but because the application of taxation was complicated by a number of fundamental issues. These complications included (1) problems associated with definitions, (2) lack of consensus about the evidence supporting a focus on these foods, (3) significant complexity around the energy or nutrient density of these foods and how this content would be taxed, (4) the power of specific companies and the food industry, (5) equity issues associated with food security for those on low incomes, and (6) the increasing presence of unhealthy foods in society.

A member of the panel provided a different perspective on food taxation complexities by saying:

"People get this analogy with smoking but it is not like smoking. There is no benefit at all in smoking, just pure danger, but with food, it's not like that. It's a gradient so therefore what do you tax?"

\section{Issues and barriers associated with taxation Food category and product definitions}

The expert panel frequently discussed problems with definitions of certain food products when considering taxation. For example, what constitutes a snack or treat? How do we define fast food? It was thus identified that the ambiguity regarding definitions associated with particular food categories makes it difficult to conceptualise how a strategy such as taxation might be effective in reducing unhealthy food consumption. In relation to "fast food", panel members discussed iconic fast food chains as most representative of typical fast food. On the other hand, they were unsure whether purchasing a salad-laden burger from a hamburger shop or franchises selling healthier options would still be considered as fast food. Discussion was held around whether foods and beverages should be defined based on attributes such as their nutrient content or portion size.

In terms of portion sizes of food items, a major concern is the relationship between energy density and nutrient value. Thus in relation to childhood food intake, not only does the type of food need to be considered but also the serving size provided. The panel discussed the importance of identifying where the bulk of the energy intake is coming from in the $0-5$ years age group. It was highlighted that sweet snacks is what partly drives the energy density increase in young children. Overall, energydense and nutrient-poor foods provide a substantial portion of children's energy intake. This raised the notion of how taxation could be considered using energy density as a potential criterion, yet no easy solutions were conceivable.

\footnotetext{
"...the little cake bars that come portion packed and are easy to buy as a snack. They are incredibly
}

difficult to define so to actually write some sort of regulation to tax them as a group would be nigh on impossible..."

Food category and product definitions were deemed to be very complex topic and the panel found it very difficult to define majority of food and drink items for the purposes of taxation. The only exception to this was sugar-sweetened drinks which were seen as potentially easier to target in terms of definition and that the public generally understand they are not a healthy choice of beverage. Furthermore, it was deemed easier to separate out soft drinks from other sugar-sweetened beverages as it is a defined product and usually marketed separately.

Apart from the challenge associated with defining various foods and beverages, the panel raised the concept of labelling foods as either 'good' or 'bad'. Some members of the panel considered it problematic to refer to foods in this manner. For example, they felt it could potentially contribute to stigma, discrimination and social alienation for people consuming such food items:

$$
\text { "...you're bad for eating that food..." }
$$

In addition to this, the panel mentioned that the public often change their reporting of food consumption, particularly under-reporting their usual intake when responding to national or state nutrition surveys; again, potentially as a result of perceptions associated with consuming less healthy food options or "bad" foods.

\section{Evidence}

The availability of scientific evidence regarding food and health was considered of utmost importance during the panel's discussions, particularly when contemplating and proposing foods that may be potentially amenable to taxation. The panel felt all discussion should be defensible and based on evidence. It was mentioned that soft drink consumption had received considerable attention in the recent past with an increasing evidence base for the potential impact of high consumption levels on health. However, evidence is not always conclusive regarding all sugar-sweetened beverage consumption and there is insufficient evidence for other food and beverage items. In a response to a lack of evidence between some foods and health, panel members noted there is a need to continually contribute to the evidence base through best practice and novel solutions to address the complexities of obesity in the early childhood years. The panel highlighted the importance of looking at consumption data and agreed this could help inform the evidence base for areas that currently do not have strong evidence. 


\section{"...I think there needs to be some action...perhaps before the conclusive evidence is there..."}

\section{Vested interests of industry players}

The panel raised the role of food companies and industry more broadly as a potential barrier to facilitation of population level policy change and regulation of unhealthy foods. For example, there was particular discussion around food companies paying exorbitant fees for shelf space in supermarkets to promote their products:

"Companies already pay for particular shelf space or pay for particular shelves and they're more than willing to do it...It works beautifully. ...the shelf that's most expensive is for the small child sitting in the shopping trolley..."

The concept of industry 'loopholes' and 'tactics' was identified in relation to companies readily changing product ingredients to meet changing food standards and requirements, thereby demonstrating efficiency in their ability to constantly adjust and adapt. Taking action to reduce unhealthy food consumption essentially means taking on some of the largest companies in the world. The panel discussed the extremely influential role of the food industry and their ability to influence eating practices of some members of society. A more appropriate balance is needed between the business imperative of industry and social responsibility, including a stronger engagement with the industry sector to effect population level policy. This is particularly challenging in the context of potential changes to taxation.

\section{Equity issues}

Members of the panel expressed concern about ensuring equity for all Australians, particularly disadvantaged populations, when considering taxation initiatives. Some panel members conveyed it would be more important for the health of disadvantaged people to subsidize healthy foods rather than increase the tax on less valuable foods:

"Poor people are the ones who are obese and we're going to tax them more. It seems very inequitable unless you then reduce the price of fruit and veg..."

\section{The increasing presence of unhealthy food in society}

The panel discussed that serving sizes or portion sizes have been changing over time and are generally becoming much larger. This demonstrates that the perception of what is 'normal' in society has been re-defined over time and has had a profound effect on food intake and how we think about food. Members of the panel expressed comments such as:
"We have redefined treats as something you have any time you want but that's not the right definition and at the same time this redefines what is normal."

Although it is feasible to investigate taxation as a means to reduce unhealthy food consumption in the early childhood years, a notion that was frequently raised during the panel discussions was the importance of promoting nutrient rich food choices for children as opposed to simply thinking about how to steer children away from foods that are detrimental to their health. The panel considered that taxation of unhealthy foods and promotion of nutrient rich food sources in combination could potentially help influence perceptions as well as social and cultural norms regarding the presence and availability of less healthy food options.

\section{Discussion}

Panel discussion resulted in a positive consensus regarding taxation of sugar-sweetened beverages. However, the overall task of identifying foods potentially amenable to taxation was evidently not an easy decision for the experts, particularly given the contribution of discussion to a significant number of barriers and issues, which subsequently played a central part in reaching consensus. Barriers such as lack of definitions for food items, portion sizes and the nutrient density of foods were deemed to hinder support for taxation methods to reduce unhealthy food consumption in the early childhood years. The effective conceptualisation of taxation is a barrier in itself [21]. This and a number of other barriers such as the role of food industry are corroborated with previous research outcomes [31]. Moreover, subsidizing fresh foods was a dominant theme in the expert panel discussions and ultimately became one of the key outcomes of consensus. Previous research however, is inconsistent regarding the effectiveness of subsidies in reducing obesity rates [21,32].

The discussion about positively impacting population health through implementation of taxation was very insightful. The expert panel contributed a range of diverse individual opinions, allowing insight to those who were supportive or against the idea of implementing food taxation. Moreover, panel members were careful in their rigorous discussion around making the assumption that introduction of food taxation would causally result in change a in consumption, however there is evidence to suggest that this might be so [21].

Panel discussion highlighted that taxation should be considered in relation to overall health, rather than taxing food solely to address the obesity crisis. A panel member went on to elaborate that there is an interest in food for many reasons other than the link to obesity and that many of the topics discussed by the panel will have an impact on disease outcomes in general. In addition to 
this, the panel thought it would be best to make broad consensus statements to highlight multiple health benefits to consumers in general, rather than specifically for young children and also highlight taxation as a package of complementary measures to make it even more effective. Thus there was unanimous agreement and acknowledgement that taxation should not occur in isolation to a suite of other strategies [33].

This research concentrates on dietary elements, specifically consumption of unhealthy or 'non-core' foods in contributing to early childhood obesity. The breadth of discussion on early childhood dietary intake continues to highlight and support the complexity of early childhood obesity with no easy answers or solutions [34]. The array of childhood obesity determinants is a dynamic interplay of genetic, perinatal and early life factors, physical inactivity, environmental factors and family factors [35]. Panel members reiterated that obesity is an extremely complex health state when considering types of foods, particular age ranges as well as the context of energy intake, energy expenditure and growth.

We believe this is the first study that explores expert opinions considering population level taxation to reduce childhood obesity. This article represents a summary of professional opinion from the unique perspective of experts in the field. Strengths of this research include utilising the nominal group technique which is still a relatively new method, particularly in the health field. The benefit is in the purpose of the technique to force a decision, no matter how hard it might be. The forced decision does not mean a correct answer has been identified [25], but in line with consensus methodology, has identified a number of potentially feasible priorities regarding food and beverage taxation and new evidence as to where public health and policy efforts could be directed.

The current research is not without its limitations. The complexity of the topic along with undertaking specific, sequential tasks meant that panel members needed to seek clarification on the process and activities on several occasions to ensure clarity and understanding. Another limitation is that although lack of definitions of food groups or items was continually identified by the panel as a significant barrier to food taxation, it was out of the scope and purpose of this research to define some of the problematic categories. Further to the research scope, this research only considered the contribution of whole foods and food items in contributing to early childhood obesity and did not delve into macro or micronutrients or a multitude of other diverse factors associated with obesity. Finally, the panel process was convened over a period of three and a half hours due to travel arrangements of experts. Regardless, a panel of longer duration may or may not have altered the outcomes of this process, given the intended purpose of forcing a decision and outcome.

One particular area for ongoing research would be to investigate the price elasticity of proposed taxable foods. In the Australian context, only broad categories of foods have been explored such as dairy, meat, fruits and vegetables [36], rather than the specific foods identified in this study and work has not focussed on the impact of changes in price in the food intake of children. This would help to theoretically identify the likely impact of taxation on consumer food choices and consumption for a range of different food and beverage items. Evidence synthesising U.S. studies [22] suggests that take away or restaurant food, soft drinks, juice, and meats are the most sensitive to price changes with a $10 \%$ increase in soft drink prices likely to decrease consumption by $8-10 \%$.

As suggested by the panel, increasing only soft drink prices however, may lead to substitution of fruit juice or other sweetened drinks thereby not having the desired outcome of reducing obesity rates. The impact of this substitution is unclear and Andreyeva and Colleagues [22] suggest that further studies are required to investigate cross-price elasticities to determine what the substitution rates will be in order to target strategies to reduce obesity effectively. Even if these foods are shown to not be particularly price sensitive or substitution occurs, taxation may still be a useful public health strategy if used to crosssubsidize healthy food options or education.

It seems imperative to generate consistent definitions or criteria to distinguish between particular food items or groups. Definitional issues are problematic for a range of different sub-disciplines of nutrition. Contribution to clarification of definitions would provide enormous benefit to a number of research endeavours within the field of health and nutrition. Finally, although we know energy-dense nutrient-poor food choices comprise a significant proportion of early childhood energy intake, it is suggested to investigate particular dietary patterns and trends of children to identify the bigger picture of diet consumption, rather than just the contribution of individual foods.

\section{Conclusion}

Results of this research highlight priority areas regarding food and beverage taxation which have applicability and relevance to developed and developing countries alike. The outcomes indicate taxation should not be dismissed in endeavours to reduce childhood obesity and could have a wider impact than just in the early childhood years. This research has contributed unique expert opinion from researchers, academics and clinicians around Australia. The expert panel explicitly identified foods contributing most to early childhood obesity and have 
proposed potential leverage points in the form of consensus outcomes where taxation may have its best chance of success - for example, taxing sugar-sweetened beverages. Future work should rigorously explore the feasibility of each individual consensus outcome in further detail.

\section{Competing interests}

The authors declare that they have no competing interests.

\section{Authors' contributions}

All authors (EP, EK, APH and TC) contributed to designing and facilitating the study. EP undertook data entry and both EP and TC contributed to the interpretation of results. All authors (EP, EK, APH and TC) contributed to writing, editing and approving the manuscript for submission.

\section{Acknowledgements}

The present study was funded by the Australian National Preventive Health Agency. (Project reference number: 17COM2011). Tracy Comans was also supported by the above grant. Erin Pitt was supported by a Griffith University Postgraduate Research Scheme scholarship. Elizabeth Kendall was supported by Griffith University and the Centre of National Research on Disability and Rehabilitation Medicine. Andrew Hills was supported by the Mater Medical Research Institute and Griffith University. Ethics approval for this research was obtained through the Griffith University Human Research Ethics Committee (HREC - MED/32/12/HREC). The authors would like to acknowledge the contribution of the Brisbane Childhood Obesity Panel and appreciation must be shown to the project's chief investigators in guiding the formation of the overall research. The authors would also like to acknowledge Angela Simons as former project manager, and Nicole Moretto and Simone Braithwaite for their independent contribution through review of the manuscript prior to submission.

\section{Author details}

'Population and Social Health Research Program, Griffith Health Institute, Griffith University, Logan Campus, University Drive, Meadowbrook, QLD 4131, Australia. ${ }^{2}$ Centre of National Research on Disability and Rehabilitation, Population and Social Health Research Program, Griffith Health Institute, Griffith University, Logan Campus, University Drive, Meadowbrook, QLD 4131, Australia. ${ }^{3}$ Griffith Health Institute, Griffith University and Mater Research Institute - The University of Queensland, Raymond Terrace, South Brisbane, QLD 4101, Australia.

Received: 2 April 2014 Accepted: 25 July 2014

Published: 8 August 2014

\section{References}

1. Hesketh KD, Campbell KJ: Interventions to prevent obesity in 0-5 year olds: an updated systematic review of the literature. Obesity 2010, 18:S27-S35.

2. Lobstein T, Baur L, Uauy R, TaskForce IIO: Obesity in children and young people: a crisis in public health. Obes Rev 2004, 5(Suppl 1):4-104.

3. Wang Y, Lobstein T: Worldwide trends in childhood overweight and obesity. Int J Pediatr Obes 2006, 1(1):11-25.

4. Australian health survey: first results, 2011-12. [http://www.abs.gov.au/ ausstats/abs@.nsf/Lookup/4364.0.55.001main+features12011-12]

5. Olds TS, Tomkinson GR, Ferrar KE, Maher CA: Trends in the prevalence of childhood overweight and obesity in Australia between 1985 and 2008 Int J Obes 2010, 34(1):57-66.

6. Booth ML, Dobbins T, Okely AD, Denney-Wilson E, Hardy LL: Trends in the prevalence of overweight and obesity among young Australians, 1985, 1997, and 2004. Obesity (Silver Spring, Md) 2007, 15(5):1089-1095.

7. World Health Organization: Population-based approaches to childhood obesity prevention. Geneva, Switzerland: World Health Organization Press; 2012.

8. Waters E, de Silva-Sanigorski A, Hall BJ, Brown T, Campbell KJ, Gao Y, Armstrong R, Prosser L, Summerbell CD: Interventions for preventing obesity in children. Cochrane Database Of Systematic Reviews (Online) 2011, 12, CD001871.
9. Campbell K, Crawford D: Family food environments as determinants of preschool-aged children's eating behaviours: implications for obesity prevention policy. A review. Australian Journal of Nutrition \& Dietetics 2001, 58(1):19-25.

10. Grieger JA, Scott J, Cobiac L: Dietary patterns and breast-feeding in Australian children. Public Health Nutr 2011, 14(11):1939-1947.

11. Birch LL, Fisher JO: Development of eating behaviors among children and adolescents. Pediatrics 1998, 101(3 Pt 2):539-549.

12. Whitaker RC, Wright JA, Pepe MS, Seidel KD, Dietz WH: Predicting obesity in young adulthood from childhood and parental obesity. New Engl J Med 1997, 337(13):869-873

13. van der Horst K, Oenema A, Ferreira I, Wendel-Vos W, Giskes K, van Lenthe F, Brug J: A systematic review of environmental correlates of obesity-related dietary behaviors in youth. Health Educ Res 2007. 22(2):203-226

14. Gortmaker SL, Swinburn BA, Levy D, Carter R, Mabry PL, Finegood DT, Huang T, Marsh T, Moodie ML: Changing the future of obesity: science, policy, and action. Lancet 2011, 378(9793):838-847.

15. Swinburn BA, Sacks G, Hall KD, McPherson K, Finegood DT, Moodie ML, Gortmaker SL: The global obesity pandemic: shaped by global drivers and local environments. Lancet 2011, 378(9793):804-814.

16. Epstein LH, Raja S, Daniel TO, Paluch RA, Wilfley DE, Saelens BE, Roemmich JN: The built environment moderates effects of family-based childhood obesity treatment over 2 years. Ann Behav Med 2012, 44(2):248-258.

17. Faith MS, Fontaine KR, Baskin ML, Allison DB: Toward the reduction of population obesity: macrolevel environmental approaches to the problems of food, eating, and obesity. Psychol Bull 2007, 133(2):205-226.

18. Cash SB, Sunding DL, Zilberman D: Fat taxes and thin subsidies: Prices, diet, and health outcomes. Acta Agriculturae Scand 2005, 2:167-174.

19. Australian Social Trends September 2012. [http://www.abs.gov.au/ AUSSTATS/abs@.nsf/allprimarymainfeatures/2A190D7FD31D727FC A257AD0000F29D2?opendocument]

20. Stafford N: Denmark cancels "fat tax" and shelves "sugar tax" because of threat of job losses. BMJ 2012, 345:e7889.

21. Mytton OT, Clarke D, Rayner M: Taxing unhealthy food and drinks to improve health. BMJ 2012, 344:e2931.

22. Andreyeva T, Long MW, Brownell KD: The impact of food prices on consumption: a systematic review of research on the price elasticity of demand for food. Am J Public Health 2010, 100(2):216-222.

23. Brownell KD, Warner KE: The perils of ignoring history: big tobacco played dirty and millions died. How similar is Big Food? Milbank Q 2009, 87(1):259-294

24. Harvey N, Holmes CA: Nominal group technique: an effective method for obtaining group consensus. Int J Nurs Pract 2012, 18(2):188-194.

25. Jones J, Hunter D: Consensus methods for medical and health services research. BMJ: British Medical Journal 1995, 311(7001):376-380.

26. Ven A, Delbecq AL: Nominal versus interactinf group processes for committee decision-making effectiveness. Acad Manag J 1971, 14(2):203-212.

27. Susskind L, McKearnan S, Thomas-Larmer J: The consensus building handbook: a comprehensive guide to reaching agreement. United Kingdom: Sage Publications; 1999.

28. Van de Ven AH, Delbecq AL: The nominal group as a research instrument for exploratory health studies. Am J Public Health 1972, 62(3):337-342.

29. Gallagher M, Hares T, Spencer J, Bradshaw C, Webb I: The nominal group technique: a research tool for general practice? Fam Pract 1993, 10(1):76-81.

30. Carney O, Mclntosh J, Worth A: The use of the Nominal Group Technique in research with community nurses. J Adv Nurs 1996, 23(5):1024-1029.

31. Powell LM, Chaloupka FJ: Food prices and obesity: evidence and policy implications for taxes and subsidies. Milbank Q 2009, 87(1):229-257.

32. Epstein $L H$, Dearing KK, Roba $L G$, Finkelstein $E$ : The influence of taxes and subsidies on energy purchased in an experimental purchasing study. Psychol Sci 2010, 21(3):406-414.

33. Bell AC, Simmons A, Sanigorski AM, Kremer PJ, Swinburn BA: Preventing childhood obesity: the sentinel site for obesity prevention in Victoria, Australia. Health Promot Int 2008, 23(4):328-336. 
34. Swinburn BA, de Silva-Sanigorski AM: Where to from here for preventing childhood obesity: an international perspective. Obesity (Silver Spring, Md) 2010, 18(Suppl 1):S4-S7.

35. Ebbeling CB, Pawlak DB, Ludwig DS: Childhood obesity: public-health crisis, common sense cure. Lancet 2002, 360(9331):473-482.

36. Seale J, Regmi A, Bernstein J: International Evidence on Food Consumption Patterns. 2003 [http://webarchives.cdlib.org/wayback.public/ UERS_ag_1/20110914164016/http://ers.usda.gov/publications/tb1904/ tb1904.pdf]

doi:10.1186/s40608-014-0015-3

Cite this article as: Pitt et al: Listening to the experts: is there a place for food taxation in the fight against obesity in early childhood?. BMC Obesity 2014 1:15.

\section{Submit your next manuscript to BioMed Central and take full advantage of:}

- Convenient online submission

- Thorough peer review

- No space constraints or color figure charges

- Immediate publication on acceptance

- Inclusion in PubMed, CAS, Scopus and Google Scholar

- Research which is freely available for redistribution 